\title{
Increased Clearance of Antipyrine and $d$-Propranolol after Phenobarbital Treatment in the Monkey
}

\author{
RELATIVE CONTRIBUTIONS OF ENZYME INDUCTION AND \\ INCREASED HEPATIC BLOOD FLOW
}

\author{
Robert A. Branch, David G. Shand, Grant R. Wilkinson, and \\ Alan S. NiES \\ From the Division of Clinical Pharmacology, Departments of Medicine and \\ Pharmacology, Vanderbilt University School of Medicine, \\ Nashville, Tennessee 37232
}

A B S T RACT The effects of phenobarbital treatment for 12 days on the regional distribution of blood flow and on the disposition of two model drugs, antipyrine and $d$-propranolol, have been determined in six unanesthetized rhesus monkeys. Phenobarbital significantly increased total hepatic blood flow from $179 \pm 15$ to $239 \pm$ $27 \mathrm{ml} / \mathrm{min}$. Liver weight was increased to a similar degree $(34 \%)$ in phenobarbital-treated animals as compared to control monkeys. The clearance of both antipyrine and $d$-propranolol was increased and the halflife decreased significantly by phenobarbital. Analysis of the data by a perfusion-limited pharmacokinetic model showed that the changes in antipyrine clearance were due almost entirely to enzyme induction. On the other hand, with $d$-propranolol, the increase in liver blood flow contributed as much to the enhanced clearance as did the stimulation of drug metabolism. The mechanism by which phenobarbital produces the frequently observed increase in drug clearance, therefore, depends upon the initial clearance value of the drug. For low clearance drugs like antipyrine, clearance changes occur largely as a result of enzyme induction. With higher clearance drugs, the effects of increased hepatic blood flow become

Dr. Branch's present address is: Department of Medicine, Bristol Royal Infirmary, Bristol, England. Dr. Shand's present address is: Department of Pharmacology, University of Florida, Gainesville, Florida 32601.

Dr. Nies is in receipt of the Pharmaceutical Manufacturers' Association Foundation Faculty Development Award.

Received for publication 22 June 1973 ard in revised form 29 October 1973. progressively more important the greater the initial clearance value.

\section{INTRODUCTION}

The ability of phenobarbital to increase the rate of elimination of a large number of drugs and hormones is generally attributed to an increase in the activity of the drug-metabolizing enzymes (1). However, phenobarbital increases hepatic blood flow in the rat (2), an effect which could also contribute to enhanced drug elimination under some circumstances (3). The effects of alterations in hepatic blood flow on hepatic drug clearance depend on the initial hepatic extraction ratio for the drug in question. Thus, changes in flow affect the clearance of drugs with an initially high hepatic extraction ratio, like lidocaine $(4,5)$, to a greater extent than those with an initially low hepatic extraction ratio, like oxyphenbutazone (6).

The dual effect of phenobarbital has been demonstrated in the present study using the unanesthetized rhesus monkey. An estimate has also been obtained of the relative contributions of enzyme induction and increased liver blood flow to the increased clearance of two model drugs, antipyrine, exhibiting a low hepatic extraction ratio, and $d$-propranolol, which has a higher extraction ratio $(7)$.

\section{METHODS}

Six male rhesus monkeys weighing from 4.3 to $5.1 \mathrm{~kg}$ (mean $4.72 \pm 0.12 \mathrm{~kg}$ ) were prepared according to Forsyth, Nies, Wyler, Neutze, and Melmon (8) by inserting in- 
TABLE I

Effect of Phenobarbital Treatment on the Regional Distribution of Blood Flow in the Monkey*

\begin{tabular}{|c|c|c|c|c|}
\hline \multirow[b]{2}{*}{ Organ } & \multicolumn{2}{|c|}{ Total flow } & \multicolumn{2}{|c|}{ Percent cardiac output } \\
\hline & Control & Phenobarbital & Control & Phenobarbital \\
\hline & \multicolumn{2}{|c|}{$\mathrm{ml} / \mathrm{min}$} & & \\
\hline Total liver & $179.4 \pm 15.0$ & $238.8 \pm 27.4 \ddagger$ & $18.7 \pm 1.1$ & $20.6 \pm 1.7$ \\
\hline Portal vein§ & $99.8 \pm 7.7$ & $139.2 \pm 10.2 \ddagger$ & $10.4 \pm 0.6$ & $12.1 \pm 1.1 \|$ \\
\hline GI tract $\Phi$ & $71.0 \pm 6.8$ & $104.4 \pm 8.5 \ddagger$ & $7.5 \pm 0.6$ & $9.1 \pm 0.9 \ddagger$ \\
\hline Stomach" & $10.8 \pm 0.5$ & $15.3 \pm 2.3$ & $1.1 \pm 0.7$ & $1.4 \pm 0.3$ \\
\hline Small intestine & $27.8 \pm 3.5$ & $43.3 \pm 2.9 \ddagger$ & $2.9 \pm 0.3$ & $3.7 \pm 0.3 \ddagger$ \\
\hline Large intestine & $28.0 \pm 3.2$ & $38.1 \pm 4.2 \ddagger$ & $2.9 \pm 0.3$ & $3.3 \pm 0.4$ \\
\hline Pancreas & $16.2 \pm 1.9$ & $19.0 \pm 1.9$ & $1.7 \pm 0.2$ & $1.6 \pm 0.1$ \\
\hline Spleen & $12.3 \pm 1.8$ & $16.2 \pm 2.9$ & $1.3 \pm 0.3$ & $1.4 \pm 0.3$ \\
\hline Hepatic artery & $79.0 \pm 9.4$ & $99.4 \pm 22.1$ & $7.9 \pm 0.9$ & $8.5 \pm 1.4$ \\
\hline Heart & $48.9 \pm 3.8$ & $56.7 \pm 4.9$ & $4.8 \pm 0.4$ & $4.9 \pm 0.4$ \\
\hline Kidneys & $137.2 \pm 14.8$ & $140.9 \pm 15.3$ & $14.4 \pm 1.6$ & $12.2 \pm 1.3$ \\
\hline Brain & $57.0 \pm 6.4$ & $76.4 \pm 8.2 \ddagger$ & $5.9 \pm 0.6$ & $6.5 \pm 0.6$ \\
\hline Bronchus & $11.3 \pm 4.1$ & $5.9 \pm 1.7$ & $1.1 \pm 0.4$ & $0.5 \pm 0.1$ \\
\hline Carcass** & $503.5 \pm 14.0$ & $612.8 \pm 56.2$ & $52.8 \pm 2.0$ & $52.8 \pm 2.9$ \\
\hline
\end{tabular}

* The average of two determinations before and after treatment was calculated in each of the six monkeys and the data computed as the mean $( \pm \mathrm{SE})$ of these average values.

$\ddagger P<0.05$ by Student's paired $t$ test.

$\S$ Portal vein $=$ gastrointestinal $(\mathrm{GI})$ tract, pancreas, spleen.

$\| 0.1>P>0.05$ by Student's paired $t$ test.

I GI tract $=$ stomach, small intestine, large intestine, mesentery.

** Carcass $=$ skeletal muscle, bone, skin.

dwelling polyvinyl catheters into the left ventricle by way of the common carotid artery. The catheters were placed subcutaneously and exteriorized near the umbilicus and the animals placed in restraining chairs in sound protected booths. All catheters were led to the outside of the booth and kept patent with a continuous infusion of $0.9 \% \mathrm{NaCl}$ solution at $0.5 \mathrm{ml} / \mathrm{h}$, allowing blood sampling, hemodynamic measurements, and drug infusions to be performed without disturbing the monkeys.

Arterial pressure and pulse rate were measured with Hewlett-Packard 1280 transducers (Hewlett-Packard Co., Palo Alto, Calif.) placed at the level of the mid-thorax and recorded on a Hewlett-Packard 7788 direct writing recorder. Cardiac outputs were measured by the dye dilution method using $0.5 \mathrm{mg}$ of indocyanine green injected into the left ventricle and withdrawing blood from the aorta at $14.8 \mathrm{ml} / \mathrm{min}$ through a Waters $\mathrm{D}-400$ cuvette densitometer (Waters Instrument, Inc., Rochester, Minn.) ; after which blood was returned to the animal. Regional distribution of blood flow was determined by the radioactive microsphere technique, using batches of $5,000-10,000$ radioactive microspheres of $50-\mu \mathrm{m}$ diameter. The full details of this technique have been reported previously $(8,9)$. By using microspheres labeled with various nuclides $\left({ }^{51} \mathrm{Cr}\right.$, ${ }^{141} \mathrm{Ce},{ }^{85} \mathrm{Sr},{ }^{125} \mathrm{I}$, or ${ }^{85} \mathrm{Nb}$ ), several serial estimates of the regional distribution of cardiac output could be made in the same animal.

2 wk after the catheters were positioned, the monkeys received steady-state infusions of antipyrine and $d$-propranolol on consecutive days in random order. A bolus of $50 \mathrm{mg} / \mathrm{kg}$ of antipyrine was followed by a constant infusion of $0.3 \mathrm{mg} / \mathrm{kg}$ per $\min$ at $0.191 \mathrm{ml} / \mathrm{min}$. A bolus of $0.5 \mathrm{mg} / \mathrm{kg}$ of $d$-propranolol was followed by a constant infusion of $6 \mu \mathrm{g} / \mathrm{kg}$ per $\min$ at $0.191 \mathrm{ml} / \mathrm{min}$. Arterial blood samples ( $4 \mathrm{ml}$ for propranolol, $3 \mathrm{ml}$ for antipyrine) were taken 30 and $60 \mathrm{~min}$ after the start of the infusion. After the second sample, the infusion was stopped, and further blood samples were taken at $15,30,45,60,90$, and $120 \mathrm{~min}$. The plasma was separated and the red cells resuspended in saline and returned to the monkey. Hemodynamic measurements and the determination of regional blood flow were performed between the two blood samples taken during the steady-state infusion of both drugs. After the control measurements, phenobarbital elixir ( $5 \mathrm{mg} / \mathrm{kg}$ per day) was administered orally for 12 days. In four monkeys the steady-state arterial concentration of antipyrine during a constant infusion was measured on successive days, and in two of these monkeys the plasma concentration of phenobarbital was also measured during phenobarbital administration. Phenobarbital was discontinued on the 12th day, and 2 days later the initial protocol for measuring the kinetics of elimination of antipyrine and $d$-propranolol was repeated. Hemodynamic data obtained during the infusions of antipyrine and $d$-propranolol did not differ significantly and were pooled for the control period and for the postphenobarbital period. However, for calculations of drug kinetics, data obtained during infusion of each drug was used. The hematocrit was measured before and after the total experiment. Organ weights of these six monkeys were compared to organ weights of 14 monkeys previously dissected in this laboratory who were not receiving phenobarbital.

Propranolol was assayed on 2-ml plasma samples by the method of Shand, Nuckolls, and Oates (10). The blood-toplasma drug concentration ratio before and after phenobarbital treatment was $0.814 \pm 0.17$. Antipyrine was assayed 

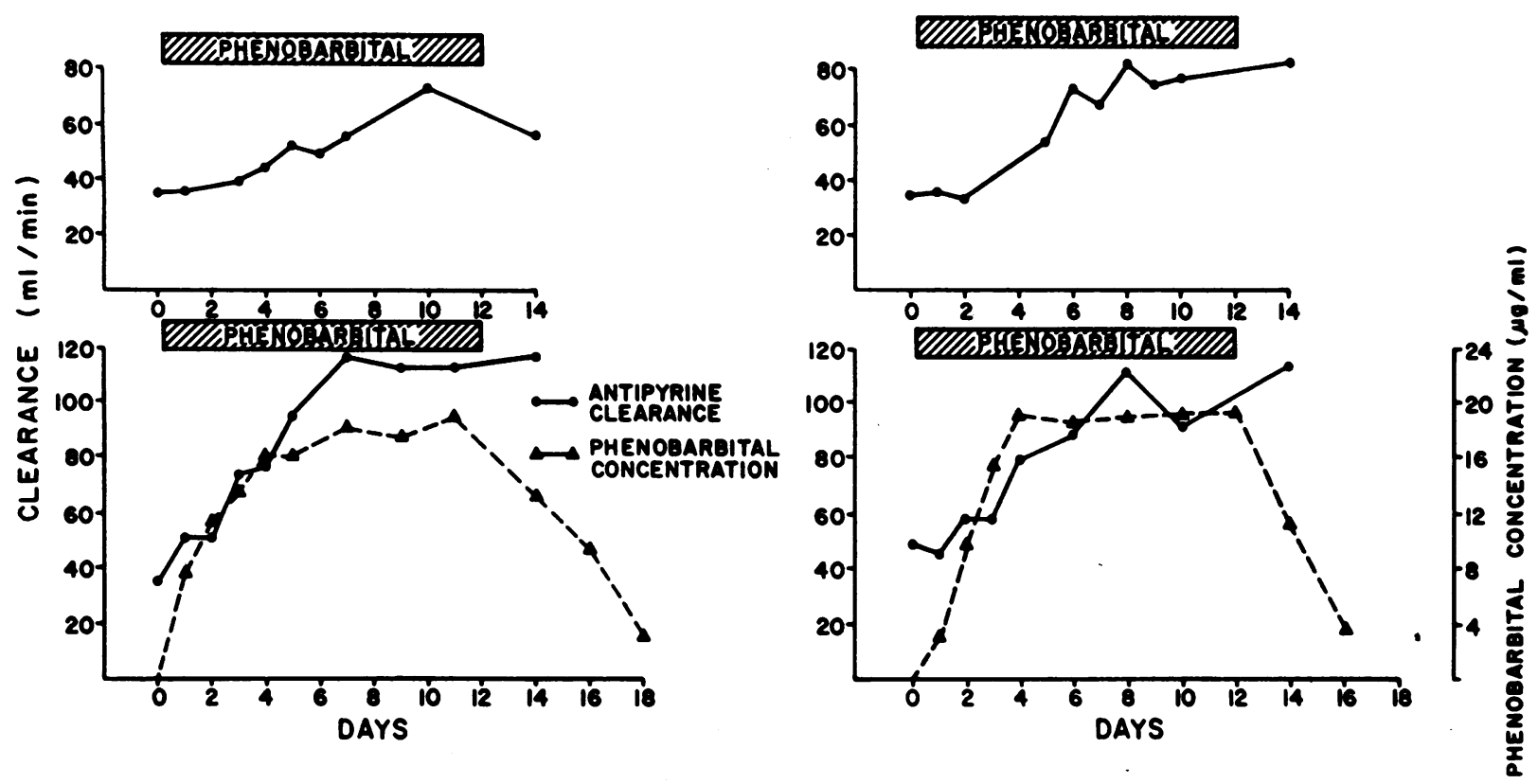

Figure 1 Time course of change in antipyrine clearance $(\bullet)$ in four individual monkeys during phenobarbital treatment. Plasma phenobarbital concentrations $(\boldsymbol{\Delta})$ were measured in two of the monkeys.

by the method of Brodie, Axelrod, Soberman, and Levy (11) and a blood-to-plasma concentration ratio of 1.0 was confirmed. Phenobarbital concentration was measured by using a modification of the gas chromatographic method of Solow and Green (12). Whole blood concentrations of the drugs were calculated as plasma concentrations $\times$ blood/ plasma ratio.

Calculations. Pharmacokinetic parameters were calculated from the following equations:

Drug clearance $=$

$$
\frac{\text { Rate of drug infusion }}{\text { Steady-state arterial blood concentration }}, \mathrm{ml} / \mathrm{min} \text {. }
$$

Volume of distribution $=\frac{\text { Clearance } \times \text { half-life }}{0.693}$, liters.

Assuming that all the drug is metabolized by the liver:

$$
\text { Hepatic extraction }=\frac{\text { Clearance }}{\text { Liver blood flow }} \text {. }
$$

Statistical analysis was performed by two-tailed Student's $t$ test on mean data before and after phenobarbital.

\section{RESULTS}

The effect of phenobarbital on regional distribution of flow. The total dissected weight of the monkeys receiving phenobarbital was $3.7 \pm 0.13 \mathrm{~kg}$ compared to $3.5 \pm$ $0.13 \mathrm{~kg}$ of 14 control monkeys similarly instrumented and restrained. The liver weights increased by $34 \%$, from $156 \pm 6.2 \mathrm{~g}$ to $209 \pm 6.1 \mathrm{~g}(P<0.001)$, and the kidney weight increased by $39 \%$ from $28.9 \pm 1.2 \mathrm{~g}$ to $40.3 \pm 3.0$ $\mathrm{g}(P<0.05)$. There were no differences in other organ weights or statistically significant changes in heart rate, stroke volume, or arterial pressure; however, cardiac output did increase from $956 \pm 26 \mathrm{ml} / \mathrm{min}$ to $1,160 \pm 76$ $\mathrm{ml} / \mathrm{min}(0.05<P<0.1)$. Although there is no relationship between the hematocrit and cardiac output in this animal preparation (8), significant changes in the hematocrit were prevented by reinfusing all red blood cells after the plasma was separated for assay (Before, $28 \pm 1.1$; after, $25.8 \pm 1.2$; change, $-2.2 \pm 1.6 ; P>0.20$ ).

After phenobarbital treatment, there was a significant $30 \%$ increase in total hepatic blood flow which resulted from the increase in portal venous blood flow. This increase in portal venous blood flow was a consequence of both an increase in the fraction of cardiac output distributed to the gastrointestinal, tract as well as the increase in cardiac output (Table I). There was also an increase in blood flow to the brain which was proportional to the increased cardiac output.

Rate of change in antipyrine clearance. Antipyrine clearance did not change until after 3 days of phenobarbital treatment, but then increased as the phenobarbital concentration exceeded $10 \mu \mathrm{g} / \mathrm{ml}$, reaching a plateau by 7 days (Fig. 1). The rate of increase in antipyrine clearance was closely paralleled by the increase in phenobarbital concentration in the two animals in which phenobarbital concentration was measured. These data suggest that the effects of phenobarbital were related to its plasma concentration and that a more rapid onset of effect might have been 
TABLE II

Influence of Phenobarbital on d-Propranolol and Antipyrine Pharmacokinetic Parameters

\begin{tabular}{|c|c|c|c|c|c|c|}
\hline & \multicolumn{3}{|c|}{$d$-Propranolol } & \multicolumn{3}{|c|}{ Antipyrine } \\
\hline & $\begin{array}{c}\text { Before } \\
\text { phenobarbital }\end{array}$ & $\begin{array}{c}\text { After } \\
\text { phenobarbital }\end{array}$ & $\begin{array}{l}\text { Percent } \\
\text { change* }\end{array}$ & $\begin{array}{c}\text { Before } \\
\text { phenobarbital }\end{array}$ & $\begin{array}{c}\text { After } \\
\text { phenobarbital }\end{array}$ & $\begin{array}{l}\text { Percent } \\
\text { change* }\end{array}$ \\
\hline $\begin{array}{l}\text { Steady-state arterial concentration, } \\
\text { propranolol, } n g / m l \text {, and } \\
\text { antipyrine, } \mu g / m l\end{array}$ & $304 \pm 3.3$ & $185.0 \pm 11_{+}^{+}$ & $-35.2 \pm 7.8 \S$ & $5.3 .7 \pm 5.8$ & $26.4 \pm 2.9_{+}^{+}$ & $-47.0 \pm 10.5 \S$ \\
\hline Half-life, $\min$ & $48.5 \pm 3.5$ & $31.8 \pm 1.2 \S$ & $-32.7 \pm 5.5 \S$ & $99.5 \pm 12.5$ & $36.7 \pm 8.1 \S$ & $-62.9 \pm 9.3 \S$ \\
\hline Clearance, $\mathrm{ml} / \mathrm{min}$ & $97.0 \pm 8.5$ & $154.0 \pm 9.1_{+}^{+}$ & $+66.8 \pm 21.4_{+}^{+}$ & $41.7 \pm 5.2$ & $9.3 .8 \pm 11.1 \S$ & $+140.0 \pm 37.2 \S$ \\
\hline Liver blood flow, $\mathrm{ml} / \mathrm{min}$ & $176.5 \pm 13.3$ & $256.3 \pm 46.0$ & $+46.7 \pm 21.9$ & $180.5 \pm 20.7$ & $221.0 \pm 13.5_{+}^{+}$ & $+26.8 \pm 9.2+$ \\
\hline Volume of distribution, liters & $6.63 \pm 0.46$ & $7.08 \pm 0.47$ & $+8.2 \pm 8.4$ & $5.84 \pm 0.72$ & $5.30 \pm 0.9$ & $-8.9 \pm 12.6$ \\
\hline Hepatic extraction ratio & $0.564 \pm 0.064$ & $0.663 \pm 0.104$ & $+31.5 \pm 33.3$ & $0.254 \pm 0.049$ & $0.438 \pm 0.065$ & $+102.0 \pm 45.2$ \\
\hline
\end{tabular}

Values are mean $\pm \mathrm{SEM}$

* Mean of the percentage changes from base line (before phenobarbital) for each animal.

$\pm P<0.05$.

$\S P<0.01$.

$\| P<0.06$.

achieved by beginning phenobarbital treatment with a loading dose.

Influence of phenobarbital on drug kinetics. 2 days after discontinuing 12 days treatment with phenobarbital the steady-state arterial concentrations and half-life of

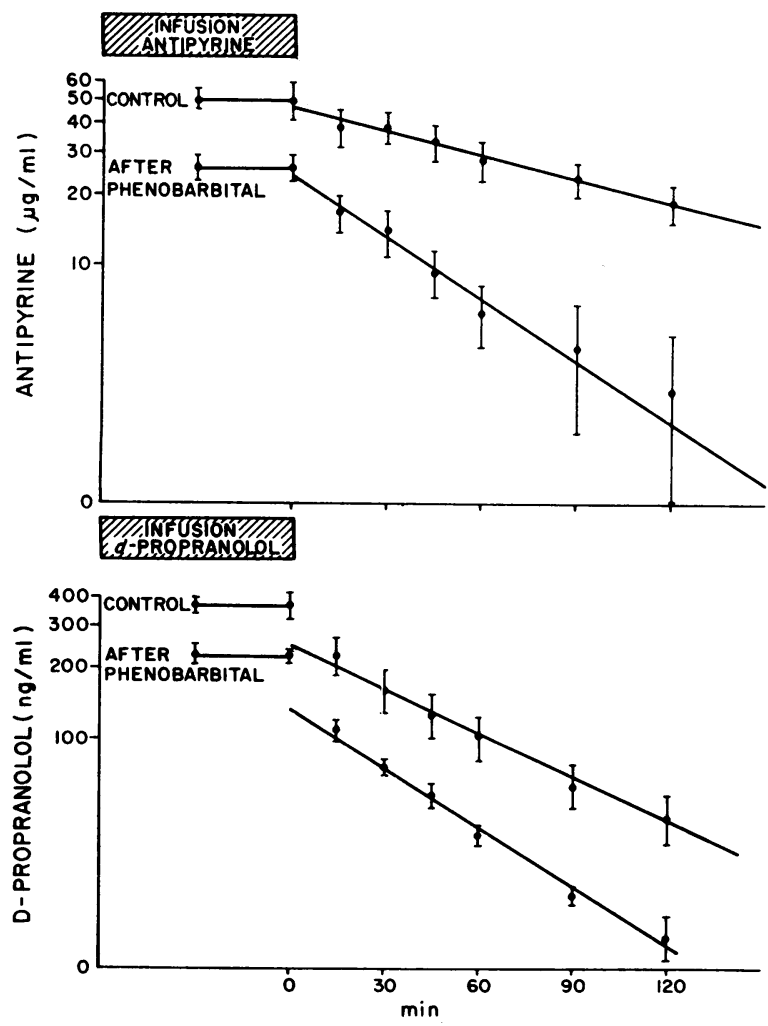

Figure 2 Steady-state concentrations and disappearance of antipyrine and $d$-propranolol concentrations before and 2 days after phenobarbital treatment for 12 days. Data plotted as the mean $\pm \mathrm{SE}$. both antipyrine and $d$-propranolol (Fig. 2) were decreased, and drug clearance increased (Table II). The hepatic extraction of propranolol and the volume of distribution of both drugs were not significantly altered. The hepatic extraction of antipyrine was increased by phenobarbital treatment, but due to the variability between animals, the change only reached borderline significance $(P<0.06)$.

\section{DISCUSSION}

The influence of phenobarbital on liver blood flow has been measured previously in the rat by using an indirect thermocouple technique; flow increases of 33-175\% (mean $79 \%$ ) were associated with a $27 \%$ increase in liver weight (2). In the present study of the rhesus monkey, the change in liver weight was very similar $(34 \%)$, and there was a proportional increase in liver blood flow. This increase in blood flow was due to a larger proportion of the cardiac output being delivered to the splanchnic circulation, as well as to an increase in total cardiac output. It is of interest to note that the increase in liver blood flow was not primarily due to an increase in hepatic artery flow, but rather to an increase in flow to the gastrointestinal tract, in particular the small intestine, without any change in weight of these organs. This is consistent with the hypothesis that total liver blood flow is regulated by a myogenic mechanism, influencing the splanchnic arterial supply more than the hepatic artery, and that the control of the total flow is closely related to liver mass (13).

This observation that phenobarbital pretreatment can increase hepatic blood flow suggests another potential mechanism for increasing drug clearance, in addition to enhancing the activity of the drug-metabolizing enzymes. The relative contributions of increased hepatic blood flow and enzyme induction, however, vary according to 
ANTIPYRINE

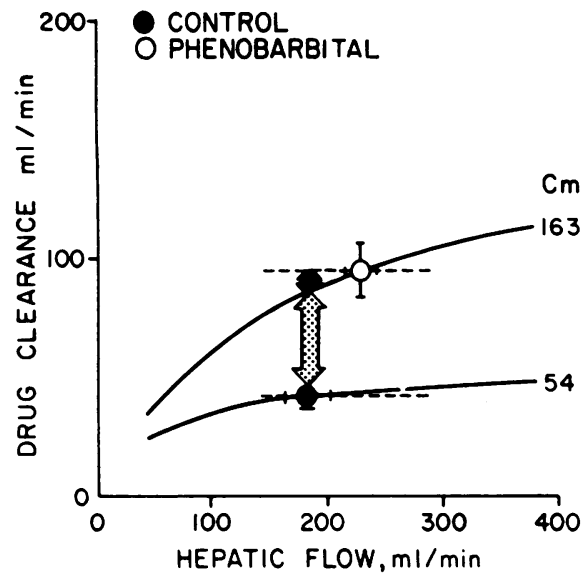

d-PROPRANOLOL

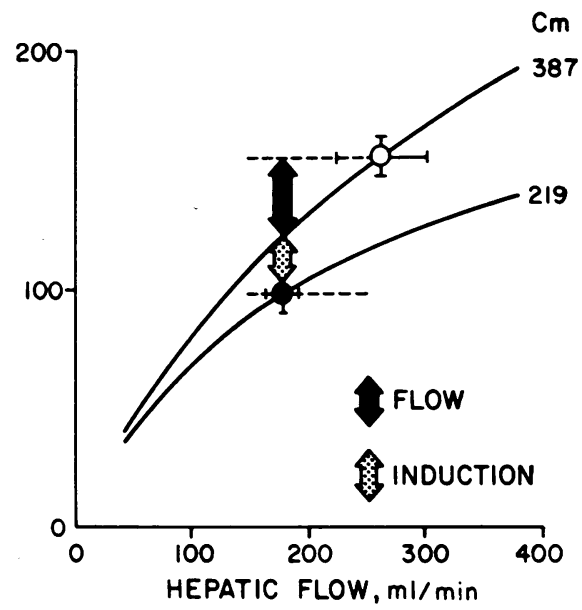

FigURE 3 Relative contributions of increased hepatic blood flow and enzyme induction to the enhanced clearance of antipyrine and $d$-propranolol. Data plotted as mean $\pm \mathrm{SE}$. See text for explanation.

whether the elimination of the drug in question is ratelimited by enzyme activity or by hepatic flow, or is influenced by both. While the rates of elimination of both antipyrine and $d$-propranolol were considerably increased by phenobarbital, it will become apparent that the mechanism of the increased clearance is different for the two compounds. The precise relationships among drug clearance, hepatic blood flow, and the activity of the drug-metabolizing enzymes are best understood by considering a perfusion-limited pharmacokinetic model (3). Assuming that $(a)$ the drug is metabolized by a first-order process, $(b)$ the hepatic venous blood is in equilibrium with drug in the liver, and $(c)$ the volume of distribution of the drug does not alter, then the following relationship is valid:

\section{Drug clearance}

$=$ Flow $\times$ hepatic extraction ratio.

$$
=\text { Flow } \times \frac{\text { Intrinsic metabolic clearance }(\mathrm{Cm})^{1}}{\text { Flow }+\mathrm{Cm}} \text {, }
$$

$\mathrm{ml} / \mathrm{min}$.

$\mathrm{Cm}$ is a function of the first-order metabolic rate constant of the drug in the liver, the hepatic partition coeffcient for the drug, and the volume of the liver. When the rate of delivery of a drug to its metabolizing enzymes is not rate-limiting, that is, when liver blood flow is considerably greater than the $\mathrm{Cm}$, actual drug clearance approaches $\mathrm{Cm}$. Thus, $\mathrm{Cm}$ represents an index of the activity of the drug-metabolizing enzymes under

${ }^{1}$ Abbreviation used in this paper: $\mathrm{Cm}$, intrinsic metabolic clearance. optimal conditions. The above relationship also indicates that, whereas liver blood flow and $\mathrm{Cm}$ are independent variables, actual drug clearance and the hepatic extraction ratio are interdependent variables. If actual drug clearance and liver blood flow are known, then $\mathrm{Cm}$ can be calculated, and from this, the change in actual clearance associated with any change in liver blood flow or $\mathrm{Cm}$ can be computed. In the present experiments, $\mathrm{Cm}$ values for both antipyrine and $d$-propranolol were calculated from liver blood flow and actual drug clearance before and after phenobarbital. The predicted relationship of actual drug clearance and liver blood flow at the calculated $\mathrm{Cm}$ before and after phenobarbital is shown in Fig. 3. Antipyrine had an initially low $\mathrm{Cm}$, resulting in a low actual drug clearance and hepatic extraction ratio at normal liver blood flow. After phenobarbital treatment, drug clearance increased considerably, largely as a result of an increase in the activity of the drug-metabolizing enzymes, which was reflected by the increase in $\mathrm{Cm}$. Thus of the increase in anti-

\section{TABLE III}

Theoretical Effects of Twofold Increases in Hepatic Blood Flow and $\mathrm{Cm}$ on the Hepatic Clearance of Drugs with Different Initial Hepatic Extraction Ratios

\begin{tabular}{lccc}
\hline & \multicolumn{3}{c}{ Hepatic extraction ratio } \\
\cline { 2 - 4 } & 0.2 & 0.5 & 0.8 \\
\hline $\begin{array}{l}\text { Relation of Cm and flow }(Q) \\
\begin{array}{c}\text { Percent increase in clearance } \\
\text { when Cm doubled }\end{array}\end{array}$ & $\mathrm{Cm}=\mathrm{Q} / 4$ & $\mathrm{Cm}=\mathrm{Q}$ & $\mathrm{Cm}=4 \mathrm{Q}$ \\
$\begin{array}{c}\text { Percent increase in clearance } \\
\text { when flow doubled }\end{array}$ & 67 & 33 & 11 \\
\hline
\end{tabular}


pyrine clearance, $85 \%$ could be accounted for by enhanced enzyme activity $(\mathrm{Cm})$, whereas only $15 \%$ was due to an increased hepatic blood flow. This is in marked contrast to the effect of phenobarbital on $d$-propranolol clearance in the same animals. With $d$-propranolol the effects of increased flow were greater because the initial $\mathrm{Cm}$ for propranolol was relatively high. Thus, only $43 \%$ of the increase in actual clearance was due to enhanced enzyme activity, while $57 \%$ of the change resulted from an increase in hepatic blood flow. It should be mentioned that these considerations apply to hepatic drug clearance and can only be extrapolated to total body drug clearance when there is little extrahepatic metabolism, as appears the case for $d$-propranolol (7) and antipyrine (14).

Certain important predictions can now be made about the effects of enzyme induction in general, and phenobarbital in particular. The usefulness of the clearance concept in the understanding of the outcome of such drug interactions cannot be overemphasized. Drug clearance, unlike half-life, provides a measure of the efficiency of the elimination process because it takes into account the extraction ratio of the organ of elimination. Thus half-life $\left(t_{\frac{1}{2}}\right)$ can only be assessed in relation to the volume of distribution $(V d)$, while drug clearance $(\mathrm{Cl})$ incorporates both these terms $(\mathrm{Cl}=\mathrm{V} d \times 0.693$ / $\left.t_{\frac{1}{2}}\right)$. Furthermore, it is drug clearance which determines the plasma concentration of a drug, which often is related to the drug's effectiveness. The effects of changes in enzyme activity (that is. $\mathrm{Cm}$ ) must always be viewed in light of hepatic blood flow and the initial $\mathrm{Cm}$. The theoretical effects of twofold increases in $\mathrm{Cm}$ and in hepatic blood flow on the hepatic clearance of three drugs with low $(0.2)$, intermediate $(0.5)$, and high $(0.8)$ hepatic extraction ratios are shown in Table III. It is evident that the lower the initial $\mathrm{Cm}$ of the drug, the greater the effect of any given degree of enzyme induction on actual drug clearance will be. This is in contrast to the effects of flow changes, which will increase with the initial drug clearance. These model predictions are supported by the available data in the literature. Thus, the clearance of a drug with a high hepatic extraction, and therefore a high $\mathrm{Cm}$ relative to liver blood flow (e.g., lidocaine), is limited by liver blood flow because hepatic extraction changes very little $(4,5)$; whereas the clearance of a drug that has a low hepatic extraction, and therefore a low $\mathrm{Cm}$ (e.g., oxyphenbutazone), is less affected by flow because the hepatic extraction changes in the opposite direction, thus "dampening" the overall effect (6). The clearance of propranolol, which has an intermediate extraction ratio in the monkey, is flowdependent (7), though not flow-limited. Importantly, these considerations seem also to apply to endogenously produced substances eliminated by the liver. Thus, the clearances of both aldosterone (15) and cortisol (16) have been shown to be flow-dependent.

The dependence of the effects of both enzyme induction and increased blood flow on the intrinsic ability of the liver to extract a given drug provides a ready explanation for the present effects of phenobarbital, which increases both enzyme activity and hepatic blood flow. This dual effect of phenobarbital will enhance the clearance of all drugs, but the dominant mechanism will depend on the initial ability of the liver to extract the drug. Enzyme induction will contribute relatively more to the increased clearance of low extraction substances, and the increase in liver blood flow will contribute relatively more to the enhanced elimination of high extraction substances. Thus the effects of phenobarbital cannot always be attributed to enzyme induction, especially in the case of high clearance compounds. For example, the enhanced clearance of indocyanine green, which has an initially high extraction ratio, (17) must be as much a result of enhanced flow as induction of a transport protein, ligandin (18). Thus, it is clear that a knowledge of a drug's hepatic extraction ratio is essential to the interpretation of drug interactions with phenobarbital, which involve increased hepatic blood flow as well as induction of both hepatic and extrahepatic drug-metabolizing enzymes.

\section{ACKNOWLEDGMENTS}

We are grateful for the expert technical assistance of Bob Rush, Jerry Strother, and Reta Cotham and to Dr. R. O. Davies of Ayerst Laboratories for the gift of $d$ propranolol.

This work was supported by U. S. Public Health Service Grant GM 15431.

\section{REFER ENCES}

1. Conney, A. H. 1967. Pharmacological implications of microsomal enzyme induction. Pharmacol. Rev. 19:317.

2. Ohnhaus, E. E., S. S. Thorgeirsson, D. S. Davies, and A. Breckenridge. 1971. Changes in liver blood flow during enzyme induction. Biochem. Pharmacol. 20: 2561.

3. Rowland, M., L. Z. Benet, and G. G. Graham. 1973. Clearance concepts in pharmacokinetics. J. Pharmacokinet. Biopharm. 1: 123.

4. Stenson, R. E., R. T. Constantino, and D. C. Harrison. 1971. Interrelationships of hepatic blood flow, cardiac output and blood levels of lidocaine in man. Circulation. 43: 205.

5. Branch, R. A., D. G. Shand, G. R. Wilkinson, and A. S. Nies. 1973. The reduction of lidocaine clearance by dl-propranolol: an example of hemodynamic drug interaction. J. Pharmacol. Exp. Ther. 184: 515.

6. Whitsett, T. L., P. G. Dayton, and J. L. McNay. 1971. The effect of hepatic blood flow on the hepatic removal rate of oxyphenbutazone in the dog. J. Pharmacol. Exp. Ther. $177: 246$.

7. Nies, A. S., G. H. Evans, and D. G. Shand. 1973. The hemodynamic effects of beta-adrenergic blockade on the flow-dependent hepatic clearance of propranolol. J. Pharmacol. Exp. Ther. 184: 716.

8. Forsyth, R. P., A. S. Nies, F. Wyler, J. Neutze, and 
K. L. Melmon. 1968. Normal distribution of cardiac output in the unanesthetized, restrained rhesus monkey. J. Appl. Physiol. $25: 736$.

9. Rudolph, A. M., and M. A. Heymann. 1967. Circulation of the fetus in utero. Methods for studying distribution of blood flow, cardiac output and organ blood flow. Circ. Res. 21: 163.

10. Shand, D. G., E. M. Nuckolls, and J. A. Oates. 1970. Plasma propranolol levels in adults with observations in four children. Clin. Pharmacol. Ther. 11: 112.

11. Brodie, B. B., J. Axelrod, R. Soberman, and B. B. Levy. 1949. The estimation of antipyrine in biological materials. J. Biol. Chem. 179: 25.

12. Solow, E. B., and J. B. Green. 1972. The simultaneous determination of multiple anticonvulsant drug levels by gas-liquid chromatography. Neurology. 22: 540.

13. Hanson, K. M., and P. C. Johnson. 1966. Local control of hepatic arterial and portal venous flow in the dog. Am. J. Physiol. 211 : 712.

14. Woodbury, D. M. 1970. Analgesic-antipyretics, anti- inflammatory agents and inhibitors of uric acid synthesis. In The Pharmacological Basis of Therapeutics. L. S. Goodman and A, Gilman, editors. The Macmillan Co., New York. 334.

15. Camargo, C. A., A. J. Dowdy, E. W. Hancock, and J. A. Luetscher. 1965. Decreased plasma clearance and hepatic extraction of aldosterone in patients with heart failure. J. Clin. Invest. 44 : 356.

16. Englert, E., Jr., R. M. Nelson, H. Brown, T. W. Nielson, and S. N. Chou. 1960. Effects of changing hepatic blood flow on 17-hydroxycorticosteroid metabolism in dogs. Surgery. $47: 982$

17 Klaassen, C. D., and G. L. Plaa. 1968. Studies on the mechanism of phenobarbital-enhanced sulfobromophthalein disappearance. J. Pharmacol. Exp. Ther. 161: 361.

18. Reyes, H., A. J. Levi, Z. Gatmaitan, and I. M. Arias. 1971. Studies of $Y$ and $Z$, two hepatic cytoplasmic organic anion-binding proteins: effect of drugs, chemicals, hormones, and cholestasis. J. Clin. Invest. 50: 2242. 